\title{
The Effect of Breed, Parity, and Stage of Lactation on Conjugated Linoleic Acid (CLA) in Milk Fat from Dairy Cows ${ }^{1}$
}

\author{
J. A. Kelsey, ${ }^{\star, 2}$ B. A. Corl, ${ }^{*}$ R. J. Collier, $†$ and D. E. Bauman* \\ *Department of Animal Science, Cornell University, Ithaca, NY 14853 \\ †Department of Animal Science, University of Arizona, Tucson, AZ 85721
}

\begin{abstract}
Dairy products are the main source of conjugated linoleic acid (CLA), a functional food component with health benefits. The major source of $c i s-9$, trans-11 CLA in milk fat is endogenous synthesis via $\Delta^{9}$-desaturase from trans-11 18:1, with the remainder from incomplete rumen biohydrogenation of linoleic acid. Diet has a major influence on milk fat CLA; however, effects of physiological factors have received little attention. Our objectives were to examine milk fat content of CLA and the CLA-desaturase index with regard to: 1) effect of breed, parity, and stage of lactation, and 2) variation among individuals and the relationship to milk and milk fat. Holstein $(n=113)$ and Brown Swiss $(n=106)$ cows were fed a single diet and milk sampled on the same day to avoid confounding effects of diet and season. Frequency distributions demonstrated that milk fat content of CLA and CLA-desaturase index varied over threefold among individuals, and this needs to be considered in the design of experiments. Holsteins had a higher milk fat content of CLA and CLA-desaturase index, but breed differences were minor. Parity and days in milk also had little or no relationship to the individual variation for these two CLA variables. Breed, parity, and days in milk accounted for $<0.1,<0.3$, and $<2.0 \%$ of total variation in CLA concentration in milk fat, respectively. Milk fat content of CLA and CLA-desaturase index were essentially independent of milk yield, milk fat percent, and milk fat yield. We speculate that the basis for the genetic variation among individuals is related to rumen output of trans-11 18:1 and to a lesser extent cis-9, trans-11 CLA, and to the tissue amount and activity of $\Delta^{9}$-desaturase.
\end{abstract}

Received January 28, 2003.

Accepted March 18, 2003.

Corresponding author: Dale E. Bauman; e-mail: deb6@cornell.edu.

${ }^{1}$ Supported in part by Cornell Agricultural Experiment Station. JAK was supported by the Cornell Presidential Research Scholars Program.

${ }^{2}$ Present address: Department of Animal and Veterinary Science, 316 Agriculture Biotechnology Bldg., University of Idaho, Moscow, ID 83844 .
(Key words: breed, conjugated linoleic acid, desaturase index, milk fat)

Abbreviation key: CLA = conjugated linoleic acid.

\section{INTRODUCTION}

Conjugated linoleic acid (CLA) is a term representing a mixture of positional and geometric isomers of octadecadienoic acid with a conjugated double bond system. Conjugated linoleic acid has been shown to possess a number of health benefits based on biomedical studies across a variety of animal models. These include anticarcinogenic, anti-atherogenic, anti-obesity, anti-diabetic and immune system enhancement [see reviews: McGuire and McGuire (2000), Belury (2002)]. These effects may be related to specific CLA isomers, and this is an active area of research.

cis-9, trans-11 Conjugated linoleic acid is the major CLA isomer found in dairy products accounting for 75 to $90 \%$ of the total CLA in milk fat (Bauman et al., 2003). This CLA isomer has been established as having anti-carcinogenic properties when included as a dietary supplement or consumed as a natural component of foods (Ip et al., 1999). The cis-9, trans-11 CLA in milk fat is primarily a product of endogenous synthesis via the enzyme $\Delta^{9}$-desaturase, with the substrate being trans-11 18:1, an intermediate formed in rumen biohydrogenation of linoleic and linolenic acids [see reviews: Bauman et al. (2001, 2003)]. A CLA-desaturase index can be calculated from the product-substrate relationship between cis-9, trans-11 CLA and trans-11 18:1 and this serves as a proxy for $\Delta^{9}$-desaturase (Bauman et al., 2001). Conjugated linoleic acid is also an intermediate in the rumen biohydrogenation of linoleic acid, and some escapes complete biohydrogenation and provides the remainder of the CLA in milk fat.

Diet has a major influence on milk fat CLA, and this has been extensively investigated [see reviews: Bauman et al. (2001), Chilliard et al. (2001)]. By manipulating the diet of dairy cows, the CLA content of milk fat can be varied over fivefold. In contrast, effects of physiological factors such as breed, stage of lactation, and parity on the CLA in milk fat and the CLA-desatur- 
Table 1. Ingredient and chemical composition of experimental diet.

\begin{tabular}{lc}
\hline Composition & Content \\
\hline Ingredients, \% of DM & \\
Alfalfa hay & 36.85 \\
Steam flaked corn & 28.16 \\
Whole cottonseed & 6.94 \\
Soybean hulls & 6.94 \\
Fat bran, 20\% tallow & 6.94 \\
Corn distillers grain & 5.93 \\
Vitamin and mineral supplement ${ }^{1}$ & 4.07 \\
Molasses & 3.18 \\
Energy II & 0.97 \\
Chemical composition, ${ }^{2} \%$ of DM & \\
CP & 17.16 \\
NDF & 28.17 \\
ADF & 18.95 \\
EE & 6.88 \\
Ca & 1.10 \\
P & 0.42 \\
$\mathrm{NE}_{1}$ (Mcal/kg of DM) & 1.85 \\
\hline
\end{tabular}

${ }^{1}$ Composition (\%) of the supplement: blood meal, 35.27; sodium bicarbonate, 19.60; calcium 38\%, 10.20; mono-dical 21\%, 10.20; menhaden fishmeal (ruminant grade), 9.80; magnesium oxide, 6.80; salt, 2.55; tallow, 2.50; yeast culture, 0.86; MTB 100 binder, 0.85; trace mineral proteinates, 0.62 ; zinc sulfate, 0.25 ; manganese sulfate, 0.21 ; vitamin E, 0.08; copper sulfate 27, 0.08; vitamin A (39,382 IU/kg), 0.07; bran, 0.05 ; sodium selenite $4.5 \%, 0.02$; cobalt carbonate, 0.01 ; and potassium iodine, 0.0025 .

${ }^{2}$ Wet chemistry analysis of the diet was performed by Chandler Analytical Laboratories (Chandler, AZ). Dry matter averaged $58.14 \%$.

ase index have received little attention. Therefore, objectives of the present study were to examine the milk fat content of CLA and the CLA-desaturase index with regard to: 1) effect of breed, parity, and stage of lactation, and 2) the variation among individuals and relationship to milk yield and milk fat.

\section{MATERIALS AND METHODS}

Lactating Holstein ( $\mathrm{n}=113 ; 49$ primiparous and 64 multiparous) and Brown Swiss ( $\mathrm{n}=106 ; 47$ primiparous and 59 multiparous) dairy cows, from the University of Arizona herd were used. All cows were fed an identical TMR (Table 1) formulated to meet or exceed nutrient requirements (NRC, 2001). Milk samples were obtained from the daily milkings on January 30, 2001, and a composite milk sample was formed for each cow. One aliquot was sent to the Arizona DHIA (Tempe, AZ) where milk fat and true protein were analyzed using AOAC approved infrared analysis equipment and procedures. Equipment and procedures are also certified each year by National DHIA. Another aliquot of the milk composite was centrifuged at $17,800 \times g$ for 30 min at $8^{\circ} \mathrm{C}$, and 300 to $350 \mathrm{mg}$ of the fat cake was removed, frozen, and shipped to Cornell University. The fat cake was stored at $-20^{\circ} \mathrm{C}$ until fatty acid analysis.

\section{Fatty Acid Analysis and Calculations}

Lipid extraction of milk fat was performed according to Hara and Radin (1978) as described by Chouinard et al. (1999). Milk fatty acids were transesterified with sodium methoxide according to the method of Christie (1982) with modifications. Hexane was added to $40 \mathrm{mg}$ of butter oil followed by $40 \mu \mathrm{l}$ of methyl acetate. The mixture was vortexed and $40 \mu \mathrm{l}$ methylation reagent ( $1.75 \mathrm{ml}$ of methanol: $0.4 \mathrm{ml}$ of $5.4 \mathrm{M}$ sodium methylate) was added. The mixture was vortexed, allowed to react for $10 \mathrm{~min}$, and then $60 \mu \mathrm{l}$ of termination reagent $(1 \mathrm{~g}$ of oxalic acid/30 ml of diethyl ether) was added. Several grains of anhydrous $\mathrm{CaCl}_{2}$ were added and the solution incubated at room temperature for $1 \mathrm{~h}$. The sample was then centrifuged for $5 \mathrm{~min}$ at $2400 \times g$ at $4^{\circ} \mathrm{C}$, and the hexane layer was removed and used directly for chromatographic determination.

Fatty acid methyl esters were analyzed by gas chromatography (Hewlett Packard GC system 6890+ with a flame-ionization detector) using a SP-2560 capillary column $(100 \mathrm{~m} \times 0.25 \mathrm{~mm}$ i.d. with $0.2-\mu \mathrm{m}$ film thickness; Supelco Inc., Bellefonte, PA). The analysis involved a programmed run with temperature ramps under conditions and temperatures as described by Baumgard et al. (2001). Each peak was identified and quantified using pure methyl-ester standards (NuChek Prep, Elysian, MN). A butter reference standard (CRM 164; Commission of the European Communities, Community Bureau of Reference, Brussels, Belgium) was analyzed at regular intervals for quality control purposes and was also used to determine recoveries and correction factors for individual fatty acids.

The fatty acid composition of milk fat is expressed as amount of each individual fatty acid per total fatty acids present. This involved transforming the data from gas chromatographic analysis (fatty acid methyl esters) to a fatty acid basis. Conjugated linoleic acid concentrations are generally expressed as milligrams per gram of fatty acids as is typical for scientific literature on CLA. The desaturase index was also calculated for four pairs of fatty acids that represent products and substrates for $\Delta^{9}$-desaturase. These fatty acid pairs were cis-9 14:1/14:0, cis-9 16:1/16:0, cis-9 18:1/18:0, and cis-9, trans-11 CLA/trans-11 18:1. We defined the desaturase index as follows: [product of $\Delta^{9}$-desaturase]/[product of $\Delta^{9}$-desaturase + substrate of $\Delta^{9}$-desaturase]. For example, the CLA-desaturase index would be calculated as:

$$
\begin{gathered}
{[c i s-9, \text { trans-11 CLA }] /} \\
{[c i s-9, \text { trans-11 CLA + trans-11 18:1] }}
\end{gathered}
$$

\section{Statistical Analysis}

The general linear model procedure (PROC GLM) of SAS (2000) was used to develop a regression model for 
KELSEY ET AL.

Table 2. Performance of lactating dairy cows on the day of sampling. ${ }^{1}$

\begin{tabular}{|c|c|c|c|c|}
\hline \multirow[b]{2}{*}{ Variable } & \multicolumn{2}{|c|}{ Holstein } & \multicolumn{2}{|c|}{ Brown Swiss } \\
\hline & Mean & Range & Mean & Range \\
\hline Parity & 2.5 & $1-10$ & 2.1 & $1-8$ \\
\hline Days in milk & 176 & $13-533$ & 182 & $8-624$ \\
\hline Milk yield, $\mathrm{kg} / \mathrm{d}$ & $38.0 \pm 0.8$ & $16.5-61.5$ & $31.5 \pm 0.8$ & $11.2-57.4$ \\
\hline \multicolumn{5}{|l|}{ Milk protein ${ }^{2}$} \\
\hline$\%$ & $3.03 \pm 0.02$ & $2.50-3.80$ & $3.46 \pm 0.02$ & $2.60-4.10$ \\
\hline $\mathrm{kg} / \mathrm{d}$ & $1.13 \pm 0.02$ & $0.53-1.82$ & $1.08 \pm 0.02$ & $0.40-1.67$ \\
\hline \multicolumn{5}{|l|}{ Milk fat } \\
\hline$\%$ & $3.41 \pm 0.06$ & $2.00-6.10$ & $3.86 \pm 0.06$ & $1.90-5.70$ \\
\hline $\mathrm{kg} / \mathrm{d}$ & $1.28 \pm 0.03$ & $0.54-2.28$ & $1.21 \pm 0.03$ & $0.31-2.12$ \\
\hline
\end{tabular}

${ }^{1}$ Milk samples were taken from Holstein $(\mathrm{n}=113)$ and Brown Swiss $(\mathrm{n}=106)$ dairy cows on the same day, while all cows were consuming the same diet. Performance variables represent means \pm SE for respective breeds after accounting for the effects of parity and days in milk.

${ }^{2}$ True protein.

analyzing these data. Categorical predictors of breed (Holstein and Brown Swiss) and parity (primiparous: lactation $=1$ and multiparous: lactation $\geq 2$ ) were included in the model. To evaluate the effect of stage of lactation, the general linear test was used to test for polynomials of DIM up to DIM ${ }^{6}$ and significant interactions. Polynomials beyond the quadratic term for DIM were not significant and none of the tested interactions were significant. Based on these tests, the final model utilized was:

$$
\mathrm{Y}_{\mathrm{ijk}}=\beta_{\mathrm{o}}+\beta_{1} \mathrm{~B}_{\mathrm{i}}+\beta_{2} \mathrm{P}_{\mathrm{j}}+\beta_{3} \mathrm{D}_{\mathrm{k}}+\beta_{3} \mathrm{D}_{\mathrm{k}}^{2}+\varepsilon_{\mathrm{ijk}},
$$

where $Y_{i j k}$ is the response variable, $B_{i}$ is the ith breed, $\mathrm{P}_{\mathrm{j}}$ is the jth parity, $\mathrm{D}_{\mathrm{k}}$ is the kth DIM, and $\varepsilon_{\mathrm{ijk}}$ is the residual error term. Correlation of ratios for the fatty acid pairs representing the desaturase index were determined using the correlation procedure (PROC CORR) of SAS (2000).

\section{RESULTS AND DISCUSSION}

\section{General Characteristics and Milk Composition}

Characteristics, milk production, and milk composition averages are presented in Table 2. Average parity and DIM were similar for the two breeds. In general, milk production and milk composition were characteristic of each breed. Holstein cows had greater milk production, whereas Brown Swiss cows on average had higher milk content of fat and protein. As a result, daily yields of milk fat and milk protein were similar between the two breeds. Earlier studies demonstrated similar patterns between Holstein and Brown Swiss in milk yield and the content and yield of fat and protein (see review by Jenness, 1985).
Milk fatty acid composition is presented in Table 3. Of total fatty acids (weight basis), short- and mediumchain length fatty acids ( $<16$ carbons) represented $21.4 \%$ for Holsteins and 23.2\% for Brown Swiss. Similar values for 16 carbon fatty acids were 29.4 and $29.5 \%$ for the two breeds and longer-chain fatty acids ( $>16$ carbons) represented $49.2 \%$ and $47.4 \%$ of total fatty acids for Holstein and Brown Swiss cows, respectively. Similarities in milk fatty acid composition between Holstein and Brown Swiss have been observed previously by DePeters et al. (1995). Jensen (2002) authored an extensive review of the fatty acid composition of bovine milk, and he pointed out that data are limited where modern analytical methods and large sample sets were utilized. The present study represents a large dataset that illustrates the pattern and individual variation in the fatty acid composition of milk fat, but it is limited to a single herd and a single diet.

One objective was to evaluate the effect of breed, parity, and DIM on milk fat content of CLA. This same model was applied to all fatty acids, and Table 4 presents the significance level for the model terms for individual fatty acids. Breed, parity, and DIM had significant effects on many of the fatty acids. Total variation for each fatty acid and the proportion of variation accounted for by the model and specific model terms are shown in Table 5. In general, the model accounted for less than $25 \%$ of total variation. Thus, breed, parity, and DIM accounted for only a small proportion of the total variation that existed for individual fatty acids.

\section{Milk Fat Conjugated Linoleic Acid}

The cis-9, trans-11 CLA in milk fat originates from the incomplete biohydrogenation of polyunsaturated fatty acids, and diet can have a major impact on the milk fat content [see reviews by Bauman et al. (2001), 
Table 3. Milk fat composition. ${ }^{1}$

\begin{tabular}{|c|c|c|c|c|}
\hline \multirow[b]{2}{*}{ Variable } & \multicolumn{2}{|c|}{ Holstein } & \multicolumn{2}{|c|}{ Brown Swiss } \\
\hline & Mean \pm SE & Range & Mean \pm SE & Range \\
\hline \multicolumn{5}{|l|}{ Fatty acid, \% } \\
\hline 4:0 & $4.61 \pm 0.11$ & $2.66-9.45$ & $5.18 \pm 0.11$ & $3.15-7.73$ \\
\hline $6: 0$ & $1.91 \pm 0.02$ & $1.27-2.61$ & $2.05 \pm 0.02$ & $0.67-2.73$ \\
\hline $8: 0$ & $0.99 \pm 0.02$ & $0.52-1.31$ & $1.12 \pm 0.02$ & $0.23-1.49$ \\
\hline $10: 0$ & $2.11 \pm 0.04$ & $0.89-2.86$ & $2.41 \pm 0.04$ & $0.36-3.53$ \\
\hline $12: 0$ & $2.29 \pm 0.04$ & $0.92-3.16$ & $2.62 \pm 0.04$ & $0.43-3.83$ \\
\hline 14:0 & $8.15 \pm 0.10$ & $4.16-10.91$ & $8.53 \pm 0.10$ & $2.55-10.54$ \\
\hline $14: 1$, cis-9 & $0.61 \pm 0.02$ & $0.14-1.23$ & $0.60 \pm 0.02$ & $0.16-1.15$ \\
\hline $15: 0$ & $0.74 \pm 0.01$ & $0.50-1.44$ & $0.69 \pm 0.01$ & $0.37-0.99$ \\
\hline $16: 0$ & $28.05 \pm 0.13$ & $24.98-33.41$ & $28.32 \pm 0.13$ & $24.41-32.58$ \\
\hline $16: 1$, cis -9 & $1.30 \pm 0.02$ & $0.80-2.40$ & $1.13 \pm 0.02$ & $0.72-1.83$ \\
\hline $17: 0$ & $0.60 \pm 0.01$ & $0.48-0.98$ & $0.59 \pm 0.01$ & $0.48-1.10$ \\
\hline 18:0 & $12.27 \pm 0.17$ & $6.63-18.29$ & $11.85 \pm 0.17$ & $8.43-20.73$ \\
\hline $18: 1$, trans -4 & $0.04 \pm 0.01$ & $0.03-0.08$ & $0.05 \pm 0.01$ & $0.02-0.09$ \\
\hline $18: 1$, trans -5 & $0.04 \pm 0.01$ & $0.02-0.11$ & $0.04 \pm 0.01$ & $0.02-0.06$ \\
\hline $18: 1$, trans -6 to 8 & $0.57 \pm 0.01$ & $0.42-0.78$ & $0.49 \pm 0.01$ & $0.33-0.64$ \\
\hline $18: 1$, trans -9 & $0.44 \pm 0.01$ & $0.29-0.61$ & $0.40 \pm 0.01$ & $0.30-0.50$ \\
\hline $18: 1$, trans -10 & $0.85 \pm 0.01$ & $0.61-1.89$ & $0.72 \pm 0.01$ & $0.47-0.95$ \\
\hline $18: 1$, trans -11 & $1.14 \pm 0.02$ & $0.71-2.43$ & $0.95 \pm 0.02$ & $0.60-1.81$ \\
\hline $18: 1$, trans -12 & $0.87 \pm 0.01$ & $0.57-1.23$ & $0.79 \pm 0.01$ & $0.55-0.99$ \\
\hline $18: 1, c i s-9$ & $25.01 \pm 0.22$ & $19.57-30.36$ & $24.52 \pm 0.22$ & $19.40-32.29$ \\
\hline $18: 2, c i s-9$, cis -12 & $3.62 \pm 0.04$ & $2.48-4.44$ & $3.41 \pm 0.04$ & $2.62-4.49$ \\
\hline 18:3, cis-9, cis-12, cis-15 & $0.39 \pm 0.01$ & $0.22-0.54$ & $0.38 \pm 0.01$ & $0.27-0.48$ \\
\hline $20: 0$ & $0.15 \pm 0.01$ & $0.08-0.19$ & $0.15 \pm 0.01$ & $0.10-0.18$ \\
\hline cis-9, trans-11 CLA & $0.44 \pm 0.01$ & $0.24-0.72$ & $0.41 \pm 0.01$ & $0.24-0.68$ \\
\hline Others $^{2}$ & $2.81 \pm 0.02$ & $2.31-3.66$ & $2.66 \pm 0.02$ & $1.97-3.5$ \\
\hline \multicolumn{5}{|l|}{ Desaturase index ${ }^{3}$} \\
\hline cis-9 14:1 & $0.06 \pm 0.01$ & $0.03-0.13$ & $0.06 \pm 0.01$ & $0.04-0.12$ \\
\hline cis-9 16:1 & $0.04 \pm 0.01$ & $0.03-0.08$ & $0.03 \pm 0.01$ & $0.03-0.06$ \\
\hline cis-9 18:1 & $0.67 \pm 0.01$ & $0.58-0.75$ & $0.67 \pm 0.01$ & $0.57-0.75$ \\
\hline Conjugated linoleic acid & $0.28 \pm 0.01$ & $0.15-0.37$ & $0.30 \pm 0.01$ & $0.16-0.40$ \\
\hline
\end{tabular}

${ }^{1}$ Milk samples were obtained on a single day from Holstein $(\mathrm{n}=113)$ and Brown Swiss $(\mathrm{n}=106)$ dairy cows, while all cows were consuming the same diet. Values represent actual means for respective breeds.

${ }^{2}$ Fatty acids $>16$ carbons that were present in trace amounts.

${ }^{3}$ Desaturase indexes are ratio of the $\Delta^{9}$-desaturase product divided by the sum of the $\Delta^{9}$-desaturase product and substrate as described in the Materials and Methods. For example, the desaturase index for cis-9 14:1 would be (cis-9 14:1)/(cis-9 14:1+14:0).

Chilliard et al. (2001)]. However, substantial variation in milk fat content of cis-9, trans-11 CLA is observed among individuals consuming the same diet. The individual frequency distribution of the milk fat content of CLA is presented in Figure 1. Average CLA content was $4.3 \mathrm{mg} / \mathrm{g}$ of fatty acids, but the range among individuals was approximately threefold ( 2.3 to $7.2 \mathrm{mg} / \mathrm{g}$ of fatty acid). Studies over a wide range of diets with more limited animal numbers have reported a similar range in CLA content of milk fat among individuals consuming the same diet (Jiang et al., 1996; Kelly et al., 1998a, 1998b; Lawless et al., 1998; Solomon et al., 2000; White et al., 2001; Lock and Garnsworthy, 2002; Peterson et al., 2002).

Our study design avoided confounding effects of diet and season on milk fat content of CLA by having all cows consuming the same diet and obtaining milk samples on the same day. However, we are dependent on a single milk sample for each cow. Previous studies have demonstrated that individual animals are quite consistent over time in their milk fat content of CLA, and that the hierarchy in CLA content among individuals is maintained even when cows are switched among diets that give very different values for the CLA content of milk fat (Kelly et al., 1998b; Lawless et al., 1999; White et al., 2001; Peterson et al., 2002).

The majority of the CLA in milk fat is of endogenous origin, synthesized via the enzyme $\Delta^{9}$-desaturase from trans-11 18:1, an intermediate in the rumen biohydrogenation of linoleic and linolenic acids (Griinari et al., 2000; Corl et al., 2001; Lock and Garnsworthy, 2002; Piperova et al., 2002). This enzyme also plays a critical role in maintaining fluidity of cellular membranes and milk fat (Parodi, 1982; Chilliard et al., 2000). The relationship between cis-9, trans-11 CLA, and trans-11 18:1 reflects $\Delta^{9}$-desaturase activity and can be used to calculate a CLA-desaturase index (Bauman et al., 2001). Desaturase indexes have been calculated previously by 
Table 4. Summary of significance levels for model terms for individual milk fatty acids. ${ }^{1}$

\begin{tabular}{|c|c|c|c|c|}
\hline \multirow[b]{2}{*}{ Variable } & \multicolumn{4}{|c|}{ Model term } \\
\hline & Breed & Parity & DIM & $\mathrm{DIM}^{2}$ \\
\hline \multicolumn{5}{|l|}{ Fatty acid } \\
\hline $4: 0$ & $* * *$ & **** & $* * *$ & $* * *$ \\
\hline $6: 0$ & $* *$ & $* *$ & & \\
\hline $8: 0$ & $* * *$ & $* * *$ & $*$ & $*$ \\
\hline $10: 0$ & $* * *$ & $* * *$ & $* *$ & $* *$ \\
\hline $12: 0$ & **** & $* * *$ & $* * *$ & $* * *$ \\
\hline $14: 0$ & $*$ & $* * *$ & $* * *$ & $* * *$ \\
\hline $14: 1$, cis -9 & & $* * *$ & $* * *$ & $* * *$ \\
\hline $15: 0$ & $* *$ & * & $* * *$ & ** \\
\hline $16: 0$ & & & $* * *$ & $* * *$ \\
\hline $16: 1$, cis -9 & $* * *$ & **** & $* * *$ & \\
\hline $17: 0$ & & $* *$ & $* * *$ & $* * *$ \\
\hline $18: 0$ & & $*$ & $* * *$ & $* * *$ \\
\hline $18: 1$, trans -4 & $* * *$ & $* * *$ & & \\
\hline $18: 1$, trans -5 & **** & & & \\
\hline $18: 1$, trans -6 to 8 & $* * *$ & & & \\
\hline $18: 1$, trans -9 & **** & & *** & ** \\
\hline $18: 1$, trans -10 & $* * *$ & & & \\
\hline $18: 1$, trans -11 & $* * *$ & & $* * *$ & $* * *$ \\
\hline $18: 1$, trans -12 & **** & & $* * *$ & $* * *$ \\
\hline $18: 1, c i s-9$ & & ** & & \\
\hline $18: 2, c i s-9, c i s-12$ & **** & & & \\
\hline \multicolumn{5}{|l|}{ 18:3, cis-9, cis-12, cis-15 } \\
\hline $20: 0$ & & & & \\
\hline cis-9, trans-11 CLA & $* *$ & & ** & \\
\hline Others $^{2}$ & $* * *$ & & * & \\
\hline \multicolumn{5}{|l|}{ Desaturase index ${ }^{3}$} \\
\hline cis-9 14:1 & $*$ & ** & $* * *$ & $* * *$ \\
\hline cis-9 16:1 & $* * *$ & $* *$ & $* *$ & \\
\hline cis-9 18:1 & & & $* * *$ & $* * *$ \\
\hline Conjugated linoleic acid & **** & & $* * *$ & $* * *$ \\
\hline
\end{tabular}

${ }^{1}$ A statistical model was developed to examine the effect of breed, parity, and DIM postpartum. The quadratic term for DIM squared was included in the model because it was significant for some fatty acids.

${ }^{2}$ Fatty acids $>16$ carbons that were present in trace amounts.

${ }^{3}$ Desaturase indexes are ratio of the $\Delta^{9}$-desaturase product divided by the sum of the $\Delta^{9}$-desaturase product and substrate as described in the Materials and Methods. For example, the desaturase index for cis-9 14:1 would be (cis-9 14:1)/(cis-9 14:1+14:0).

$*=P<0.05 ; * *=P<0.01 ; * * *=P<0.001$.

Malau-Aduli et al. (1997), Choi et al. (2000), Morales et al. (2000), Beaulieu et al. (2001), Lock and Garnsworthy (2002), and Peterson et al. (2002), but groups used slightly different formulas. We calculated the desaturase index as defined in the Materials and Methods, and Figure 1 (bottom panel) presents the frequency distribution of individuals for the CLA-desaturase index involving cis-9, trans-11 CLA, and trans-11 18:1. The variation among individuals represented over a threefold range. Similar individual variation was reported by Peterson et al. (2002) and Lock and Garnsworthy (2002, 2003).

Milk fat contains three additional fatty acid pairs that represent a product/substrate relationship for $\Delta^{9}$ desaturase. These are cis-9 14:1/14:0, cis-9 16:1/16:0, and cis-9 18:1/18:0. Similar to previous studies (Peterson et al., 2002), we observed that desaturase indexes based on these pairs were correlated (Table 6).
With the exception of the cis-9 16:1-desaturase index, correlation coefficients among the other desaturase indexes ranged from 0.63 to 0.87 .

Figure 2 summarizes breed effects on CLA concentration in milk fat and CLA-desaturase index. CLA content of milk fat was higher in Holsteins $(4.4 \pm 0.1 \mathrm{mg} / \mathrm{g}$ of fatty acid) than in Brown Swiss $(4.1 \pm 0.1 \mathrm{mg} / \mathrm{g}$ of fatty acid) and CLA-desaturase index also differed. Although significant $(P<0.01)$, these differences are inconsequential when compared with the effects of dietary manipulation or the variation among individuals. Breed accounted for $<0.1 \%$ of the total variation in the CLA concentration in milk fat (Table 5). We are not aware of any previous investigations of the effect of breed on desaturase index, but several studies have examined milk fat content of CLA. Lawless et al. (1999) compared four breeds, Irish Holstein/Friesian, Dutch Holstein/ Friesian, Montbeliardes, and Normandes that were 
Table 5. Percent of the variation accounted for by model terms for the milk fatty acid content of individual fatty acids.

\begin{tabular}{|c|c|c|c|c|c|}
\hline \multirow[b]{2}{*}{ Variable } & \multicolumn{2}{|c|}{ Sums of squares ${ }^{1}$} & \multicolumn{3}{|c|}{ Model $^{3}$} \\
\hline & Total & Model $\%^{2}$ & Breed & Parity & $\left(\mathrm{DIM}+\mathrm{DIM}^{2}\right)$ \\
\hline \multicolumn{6}{|l|}{ Fatty acid } \\
\hline $4: 0$ & 390.3 & 23.1 & $20.3-25.6$ & $17.7-25.3$ & $48.2-62.8$ \\
\hline $6: 0$ & 17.8 & 17.0 & $30.5-33.2$ & $27.2-37.5$ & $28.9-43.2$ \\
\hline $8: 0$ & 7.8 & 22.7 & $55.3-57.9$ & $30.4-33.4$ & $9.7-14.6$ \\
\hline 10:0 & 50.7 & 24.1 & $34.1-38.6$ & $38.1-42.2$ & $18.6-29.1$ \\
\hline $12: 0$ & 62.9 & 28.8 & $26.9-32.2$ & $26.0-33.1$ & $34.1-48.2$ \\
\hline $14: 0$ & 302.8 & 22.9 & $7.8-11.6$ & $19.3-25.1$ & $61.7-74.6$ \\
\hline $14: 1$, cis -9 & 9.0 & 34.9 & $0.0-0.6$ & $7.9-15.0$ & $83.3-93.1$ \\
\hline $15: 0$ & 2.8 & 9.5 & $34.1-40.1$ & $14.6-18.2$ & $40.5-52.2$ \\
\hline $16: 0$ & 413.5 & 9.8 & $10.0-14.4$ & $1.9-3.8$ & $81.0-89.0$ \\
\hline $16: 1$, cis -9 & 14.5 & 26.8 & $33.2-38.9$ & $7.1-13.6$ & $47.4-59.6$ \\
\hline $17: 0$ & 1.4 & 35.8 & $1.1-2.9$ & $6.1-12.1$ & $84.0-93.9$ \\
\hline $18: 0$ & 912.0 & 30.0 & $3.5-6.4$ & $1.4-4.9$ & $88.0-95.8$ \\
\hline $18: 1$, trans -4 & $<0.1$ & 12.6 & $53.4-55.9$ & $35.0-40.7$ & $4.2-11.6$ \\
\hline $18: 1$, trans -5 & $<0.1$ & 13.3 & $76.0-80.2$ & $4.4-7.5$ & $12.9-19.4$ \\
\hline $18: 1$, trans -6 to 8 & 1.1 & 28.0 & $95.8-96.4$ & $3.5-4.0$ & $0.0-0.5$ \\
\hline $18: 1$, trans -9 & 0.6 & 24.8 & $67.8-74.0$ & $0.5-1.7$ & $24.1-31.8$ \\
\hline $18: 1$, trans -10 & 5.8 & 18.3 & $93.2-94.4$ & $2.9-4.1$ & $1.4-4.4$ \\
\hline $18: 1$, trans -11 & 17.1 & 33.3 & $34.0-40.1$ & $0.0-0.5$ & $58.6-66.21$ \\
\hline $18: 1$, trans -12 & 2.6 & 21.1 & $57.4-64.0$ & $1.7-3.2$ & $32.5-41.2$ \\
\hline $18: 1$, cis -9 & 1239.5 & 9.1 & $9.6-11.7$ & $31.6-44.7$ & $43.4-59.3$ \\
\hline $18: 2, c i s-9, c i s-12$ & 43.8 & 7.5 & $74.2-75.2$ & $12.5-15.7$ & $8.1-14.5$ \\
\hline $18: 3$, cis -9, cis -12, cis -15 & 0.4 & 2.5 & $49.5-56.2$ & $5.5-8.5$ & $34.9-45.6$ \\
\hline $20: 0$ & 2.0 & 14.3 & $19.7-24.9$ & $7.6-14.6$ & $60.5-73.0$ \\
\hline cis -9, trans-11 CLA & 0.1 & 2.2 & $0.3-1.4$ & $7.7-14.5$ & $83.1-93.1$ \\
\hline Others $^{4}$ & 14.3 & 12.1 & $71.5-76.9$ & $6.7-8.7$ & $14.2-21.9$ \\
\hline \multicolumn{6}{|l|}{ Desaturase index ${ }^{2}$} \\
\hline cis-9 14:1 & 0.071 & 30.6 & $2.9-5.5$ & $2.9-8.4$ & $93.6-99.1$ \\
\hline cis-9 16:1 & 0.015 & 23.6 & $46.6-56.6$ & $6.6-13.3$ & $36.6-60.0$ \\
\hline cis-9 18:1 & 0.350 & 32.2 & $0.0-0.8$ & $0.0-0.7$ & $96.4-98.2$ \\
\hline CLA & 0.426 & 54.9 & $7.7-11.5$ & $0.0-1.5$ & $86.9-92.3$ \\
\hline
\end{tabular}

\footnotetext{
${ }^{1}$ The total and model sums of squares were obtained from the ANOVA table.

${ }^{2}$ Percent of total sums of squares accounted for by the model.

${ }^{3}$ Model terms were arranged in all possible combinations, and sequential sums of squares were used to determine the range (in percent) of the variation of the model sums of squares accounted for by each of the model terms.

${ }^{4}$ Fatty acids $>16$ carbons that were present in trace amounts.
}

grazing pasture. They reported that breed had a small effect with Montbeliardes, averaging about $13 \%$ greater CLA content in milk fat than the other three breeds. White et al. (2001) compared Holstein and Jersey cows that were either fed a TMR in confinement or grazing pasture; they found that Holstein cows had slightly higher milk fat concentrations of CLA $(\sim 18 \%$ greater overall). Whitlock et al. (2002) reported a breed $\times$ diet interaction in a study with Brown Swiss and Holstein cows, but the comparison involved only a limited number of animals (four Brown Swiss and eight Holstein). Similarly, Capps et al. (1999) and Dhiman et al. (2002) compared several dairy breeds, but both studies had only four or five cows from each breed. Given the extensive variation among individuals discussed earlier, examination of breed differences will require a significant number of animals from each breed. Nevertheless, the limited published work and the present study indicate that breed has a minimal effect on milk fat content of CLA and the CLA-desaturase index.

There were no differences in milk fat content of CLA or the CLA-desaturase index between primiparous and multiparous animals (Figure 2). Parity accounted for $<0.3 \%$ of the total variation in milk fat content of CLA (Table 5). We are not aware of any published studies that have systematically examined the effect of parity on these CLA variables. Stanton et al. (1997) included parity as a variable in two studies that examined the effect of diet on milk fat content of CLA; they found no consistent effect, although cows with greater than four parities did have a higher milk fat content of CLA than cows of two to four parities at one sampling time in one of the studies.

Figure 3 shows the relationship of DIM with milk fat content of CLA (top panel) and CLA-desaturase index (bottom panel). Stage of lactation had little effect on 

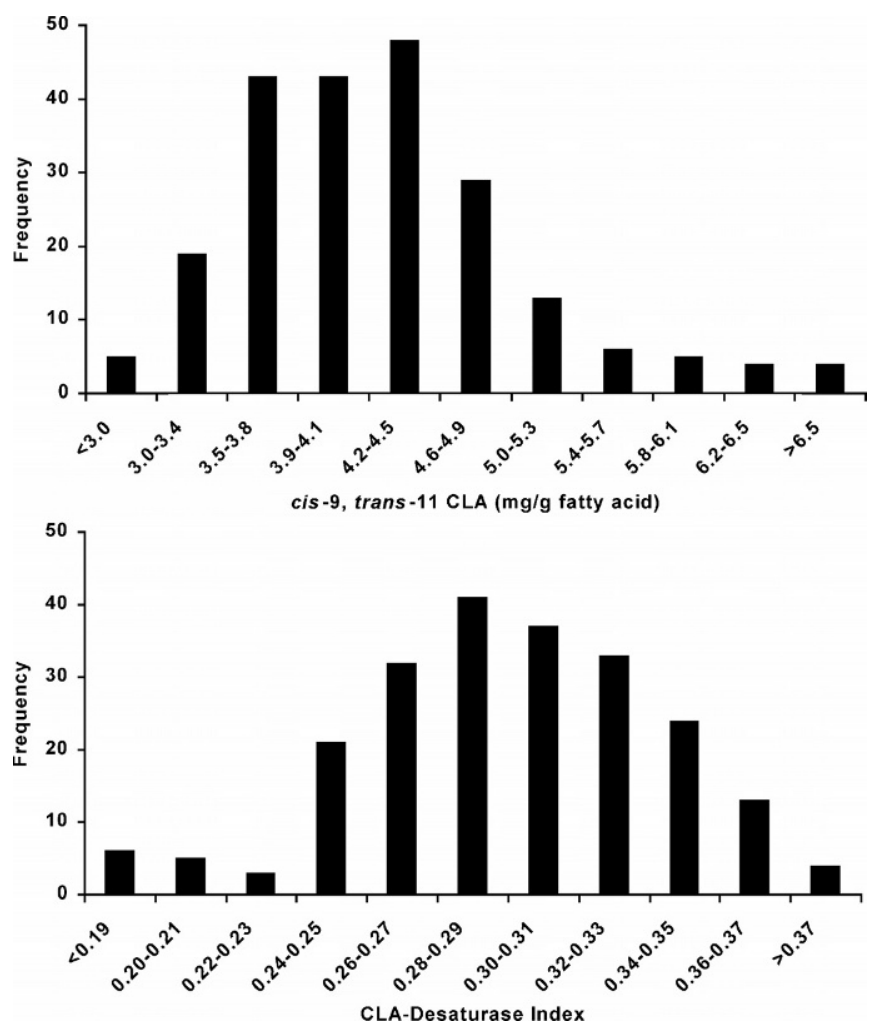

Figure 1. Frequency distribution for milk fat content of conjugated linoleic acid (CLA; top panel) and CLA-desaturase index (cis-9, trans11 CLA/cis-9, trans-11 CLA + trans-11 18:1; bottom panel). Milk samples were collected on a single day from 219 dairy cows consuming a single TMR.

these two CLA-related variables. The term DIM + DIM $^{2}$ accounted for $<2.0 \%$ of the total variation in milk fat content of CLA (Table 5). Auldist et al. (1998) examined effects of stage of lactation on milk fat content of CLA with pasture fed cows $(n=80)$; they compared early ( $\sim 30$ DIM), mid ( 120 DIM), and late ( 210 DIM) lacta-

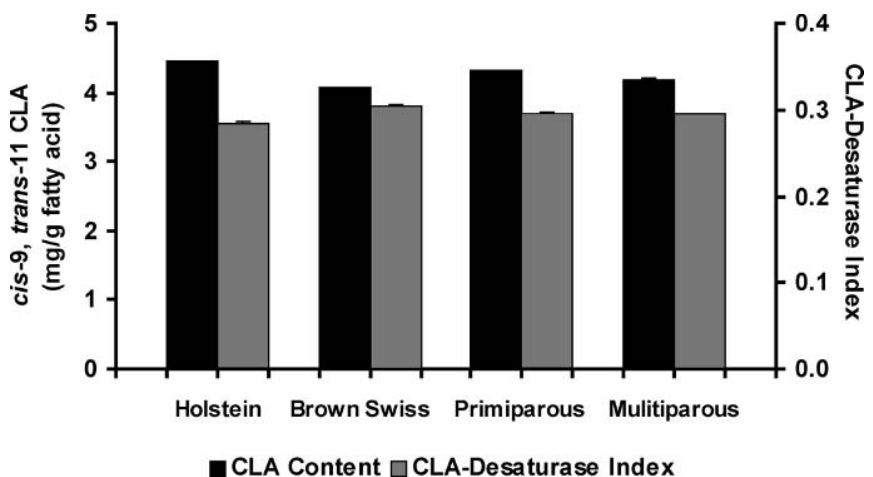

Figure 2. Milk fat content of conjugated linoleic acid (CLA; solid bars) and CLA-desaturase index (cis-9, trans-11 CLA/cis-9, trans-11 CLA + trans-11 18:1; striped bars) for dairy cows grouped by breed and parity. Milk samples were collected on a single day from 219 dairy cows consuming a single TMR and values are least squares means. Breeds differed for both CLA content and CLA-desaturase index $(P<0.01)$, whereas there were no differences for parity $(P>$ $0.05)$. Error bars corresponding to the SEM are shown $(0.007 \mathrm{mg} / \mathrm{g}$ fatty acids for CLA and 0.002 for CLA-desaturase Index).

tion and observed a small increase going from $7.9 \mathrm{mg} /$ $\mathrm{g}$ of fatty acids in early lactation to $9.7 \mathrm{mg} / \mathrm{g}$ fatty acids in late lactation. Stanton et al. (1997) reported no effect due to lactation stage on CLA levels in milk fat in two studies that were more limited in scope, the first involving 36 cows ranging from 12 to 93 DIM and the second study using 45 cows ranging from 99 to 193 DIM.

There is interest in the relationship of CLA to milk and milk fat production and the size of our dataset allows this to be examined. In the present study, milk yield ranged from 11 to $62 \mathrm{~kg} / \mathrm{d}$, milk fat percent ranged from 1.9 to $6.1 \%$, and milk fat yield ranged from 0.3 to $2.3 \mathrm{~kg} / \mathrm{d}$. Figure 4 summarizes the relationship of CLA concentration in milk fat with milk yield, milk fat percent, and milk fat yield, while the same relationships with CLA-desaturase index are presented in Figure 5.

Table 6. Correlation coefficients for desaturase indexes. ${ }^{1}$

\begin{tabular}{|c|c|c|c|c|}
\hline \multirow[b]{2}{*}{ Desaturase index } & & \multicolumn{3}{|c|}{ Desaturase index } \\
\hline & & cis-9 16:1 & cis-9 18:1 & CLA \\
\hline cis-9 14:1 & $\begin{array}{l}\text { Holstein } \\
\text { Brown Swiss } \\
\text { Combined }\end{array}$ & $\begin{array}{l}0.65^{*} \\
0.63^{*} \\
0.64^{*}\end{array}$ & $\begin{array}{l}0.65^{*} \\
0.73^{*} \\
0.67^{*}\end{array}$ & $\begin{array}{l}0.74^{*} \\
0.70^{*} \\
0.66^{*}\end{array}$ \\
\hline cis-9 16:1 & $\begin{array}{l}\text { Holstein } \\
\text { Brown Swiss } \\
\text { Combined }\end{array}$ & & $\begin{array}{l}0.55^{*} \\
0.68^{*} \\
0.54^{*}\end{array}$ & $\begin{array}{l}0.51^{*} \\
0.44^{*} \\
0.35^{*}\end{array}$ \\
\hline cis-9 18:1 & $\begin{array}{l}\text { Holstein } \\
\text { Brown Swiss } \\
\text { Combined }\end{array}$ & & & $\begin{array}{l}0.86^{*} \\
0.87^{*} \\
0.85^{*}\end{array}$ \\
\hline
\end{tabular}

\footnotetext{
${ }^{1}$ Desaturase indexes are ratio of the $\Delta^{9}$-desaturase product divided by the sum of the $\Delta^{9}$-desaturase product and substrate as described in the Materials and Methods. For example, the desaturase index for cis-9 14:1 would be (cis-9 14:1)/(cis-9 14:1+14:0).

$* P<0.0001$.
} 

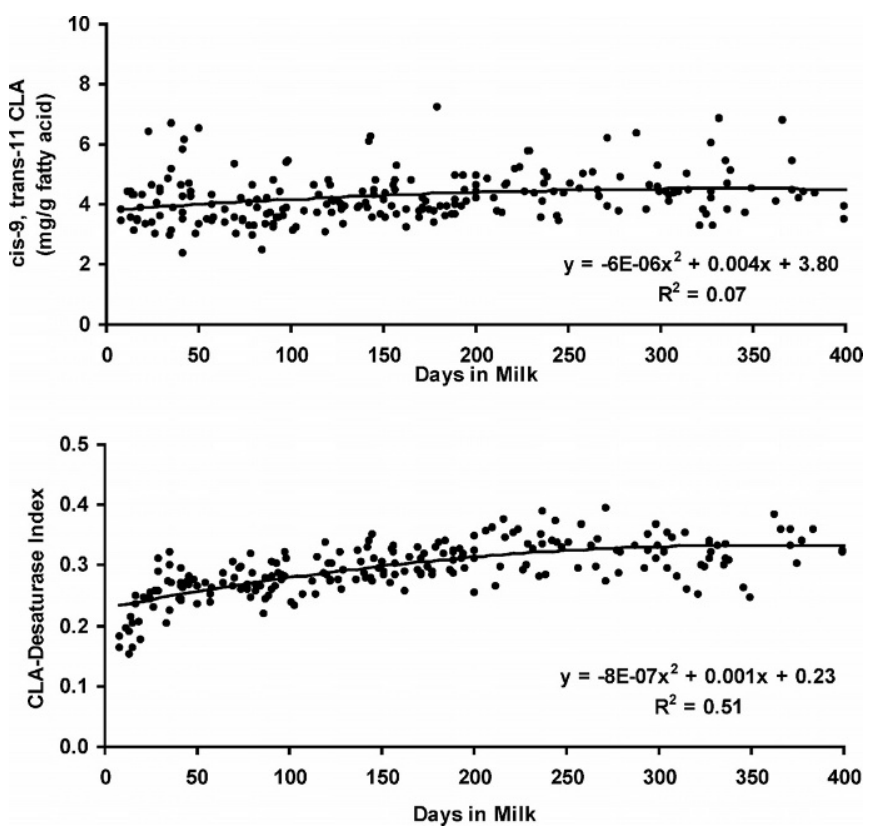

Figure 3. Relationship of DIM with milk content of conjugated linoleic acid (CLA; top panel) and CLA-desaturase index (cis-9, trans11 CLA/cis-9, trans-11 CLA + trans-11 18:1; bottom panel). Data represent milk samples collected on a single day from 219 dairy cows consuming a single TMR. Graph depicts data points for individual cows with the exception of eight cows that were $>400$ DIM.

Clearly, the yield of milk, milk fat percent, and milk fat yield have little or no impact on individual variation for these two CLA variables. There have been no previous published studies examining this, but calculations using the dataset of Lock and Garnsworthy (2003) also found that milk fat content of CLA and CLA-desaturase index were independent of milk yield and milk fat yield and milk fat percentage (Lock, personal communication).

\section{CONCLUSIONS}

Numerous investigations have demonstrated that diet has a substantial effect on the milk fat content of CLA, but physiological factors and variation among individuals has been less well studied. The present study demonstrated that the variation in both milk fat content of CLA and CLA-desaturase index was over threefold among individuals consuming the same diet; this needs to be considered in the design of experiments. Breed (Holstein vs. Brown Swiss), parity, and DIM had little relationship to the individual variation for these two CLA variables. Likewise, these CLA variables were essentially independent of milk yield, milk fat percent, and milk fat yield. Overall, the physiological and genetic basis for the individual variation in milk fat content of CLA and the CLA-desaturase index remains to

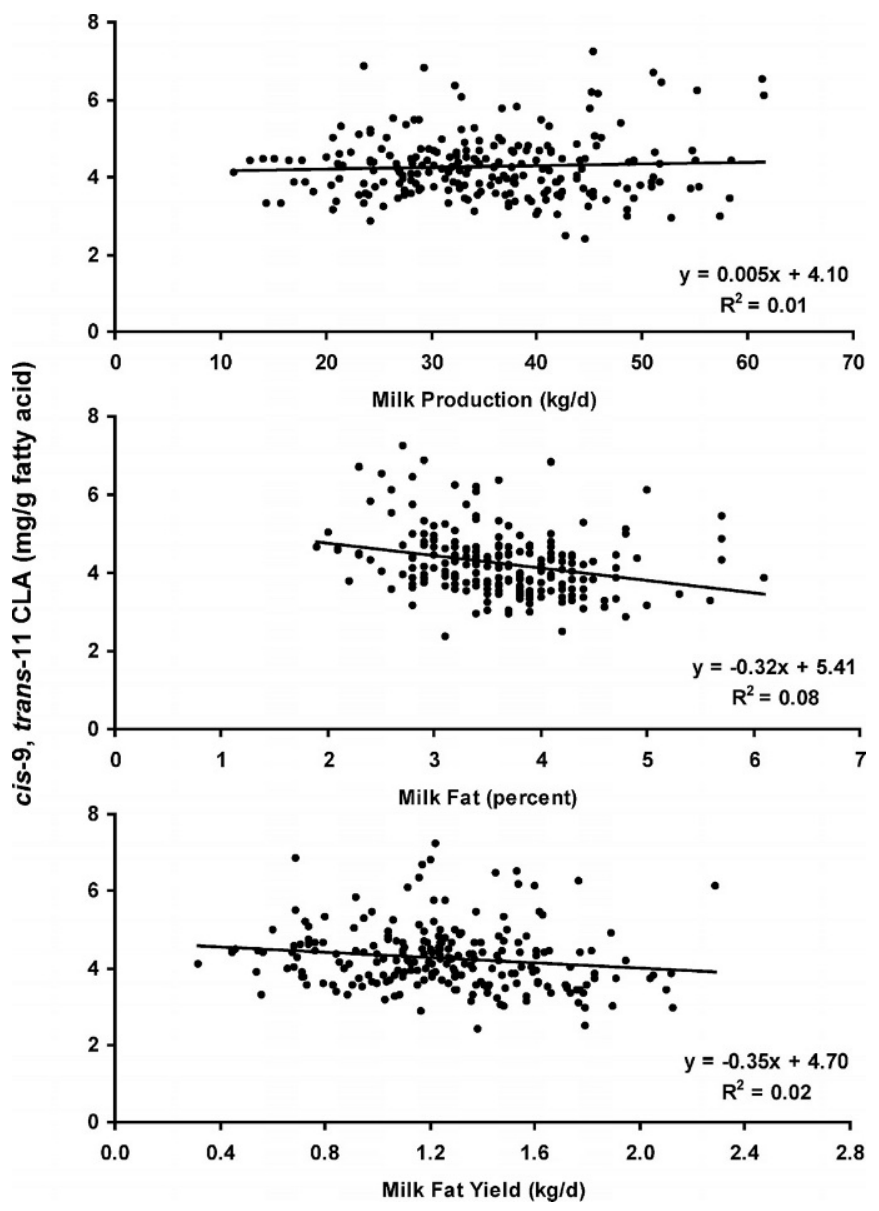

Figure 4. Relationship between milk fat content of conjugated linoleic acid (CLA) and milk production (top panel), milk fat percent (middle panel), and milk fat yield (bottom panel). Data points represent milk samples collected on a single day from 219 dairy cows consuming a single TMR.

be identified, but it must be related to two broad aspects-rumen output of trans-11 18:1 and to a lesser extent cis-9, trans-11 CLA, and to the amount and activity of $\Delta^{9}$-desaturase in tissues.

\section{ACKNOWLEDGMENTS}

The authors gratefully acknowledge the contributions of University of Arizona staff, Margaret Kattnig for sample collections, and Steve Faber for his contribution as Farm Manager. In addition, we thank Cornell University staff, D. A. Dwyer, Department of Animal Science, for technical assistance in fatty acid analysis and R. Everett, Department of Animal Science, and R. Lloyd, Department of Biometry, for assistance with statistical analysis. 

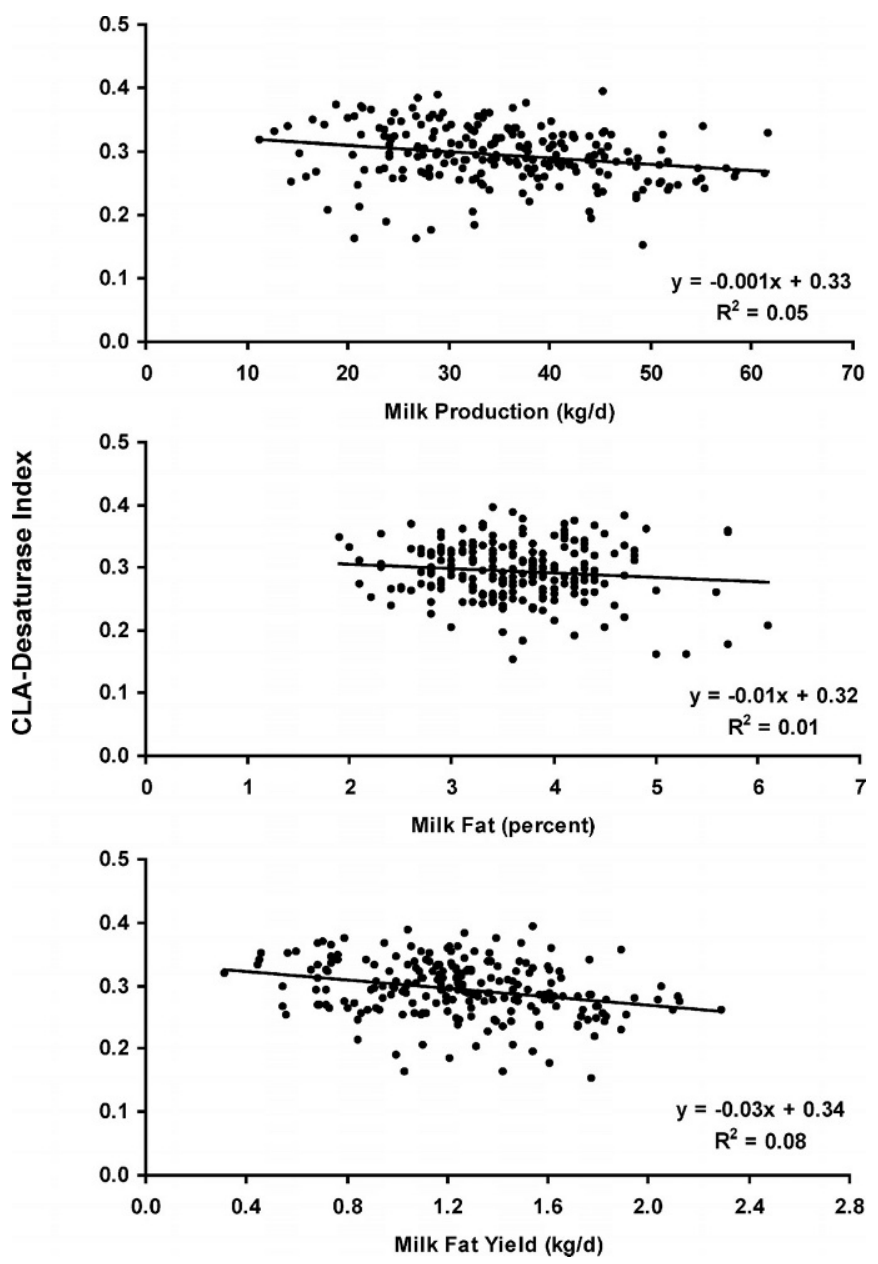

Figure 5. Relationship between CLA-desaturase index (cis-9, trans-11 CLA/cis-9, trans-11 CLA + trans-11 18:1) and milk production (top panel), milk fat percent (middle panel) and milk fat yield (bottom panel). Data represent milk samples collected on a single day from 219 dairy cows consuming a single TMR.

\section{REFERENCES}

Auldist, M. J., B. J. Walsh, and N. A. Thomson. 1998. Seasonal and lactation influences on bovine milk composition in New Zealand. J. Dairy Res. 65:401-411.

Bauman, D. E., B. A. Corl, L. H. Baumgard, and J. M. Griinari. 2001. Conjugated linoleic acid (CLA) and the dairy cow. Pages 221-250 in Recent Advances in Animal Nutrition 2001. P. C. Garnsworthy and J. Wiseman, eds. Nottingham University Press, Nottingham, UK.

Bauman, D. E., B. A. Corl, and D. G. Peterson. 2003. The biology of conjugated linoleic acids in ruminants. Pages 146-173 in Advances in Conjugated Linoleic Acid Research, Volume 2. Sebedio, J.-L., W. W. Christie, and R. O. Adlof, ed., AOCS Press, Champaign, IL.

Baumgard, L. H., J. K. Sangster, and D. E. Bauman. 2001. Milk fat synthesis in dairy cows is progressively reduced by increasing supplemental amounts of trans-10, cis-12 conjugated linoleic acid (CLA). J. Nutr. 131:1764-1769.

Beaulieu, A. D., J. K. Drackley, and N. R. Merchen. 2001. Concentrations of conjugated linoleic acid (cis-9, trans-11-octadecadienoic acid) are not increased in tissue lipids of cattle fed a high-concen- trate diet supplemented with soybean oil. J. Anim. Sci. 80:874861.

Belury, M. A. 2002. Dietary conjugated linoleic acid in health: physiological effects and mechanisms of action. Annu. Rev. Nutr. 22:505-531

Capps, V. A., E. J. DePeters, S. J. Taylor, H. Perez-Monti, J. A. Wyckoff, and M. Rosenberg. 1999. Effect of breed of dairy cattle and dietary fat on milk yield and composition. J. Dairy Sci. 82(Suppl. 1):45. (Abstr.).

Chilliard, Y., A. Ferlay, and M. Doreau. 2001. Effect of different types of forages, animal fat or marine oils in cow's diet on milk fat secretion and composition, especially conjugated linoleic acid (CLA) and polyunsaturated fatty acids. Livest. Prod. Sci. 70:31-48.

Chilliard, Y., A. Ferlay, R. M. Mansbridge, and M. Doreau. 2000. Ruminant milk fat plasticity: nutritional control of saturated, polyunsaturated, trans and conjugated fatty acids. Ann. Zootech. 49:181-205.

Choi, Y., Y. Kim, Y. Han, Y. Park, M. W. Pariza, and J. M. Ntambi. 2000 . The trans-10, cis-12 isomer of conjugated linoleic acid downregulates stearoyl-CoA desatuase 1 gene expression in 3T3-L1 adipocytes. J. Nutr. 130:1920-1924.

Chouinard, P. Y., L. Corneau, A. Sæbo, and D. E. Bauman. 1999. Milk yield and composition during abomasal infusion of conjugated linoleic acid. J. Dairy Sci. 82:2737-2745.

Christie, W. W. 1982. A simple procedure for rapid transmethylation of glycerolipids and cholesteryl esters. J. Lipid Res. 23:1072-1075.

Corl, B. A., L. H. Baumgard, D. A. Dwyer, J. M. Griinari, B. S. Phillips, and D. E. Bauman. 2001. The role of $\Delta^{9}$-desaturase in the production of cis-9, trans-11 CLA. J. Nutr. Biochem. 12:622-630.

DePeters, E. J., J. F. Medrano, and B. A. Reed. 1995. Fatty acid composition of milk fat from three breeds of dairy cattle. Can. J. Anim. Sci. 75:267-269.

Dhiman, T. R., M. S. Zaman, L. Kilmer, and D. Gilbert. 2002. Breed of dairy cows has influence on conjugated linoleic acid (CLA) content of milk. J. Dairy Sci. 85 (Suppl. 1):315. (Abstr.).

Griinari, J. M., B. A. Corl, S. H. Lacy, P. Y. Chouinard, K. V. V. Nurmela, and D. E. Bauman. 2000. Conjugated linoleic acid is synthesized endogenously in lactating dairy cows by $\Delta^{9}$-desaturase. J. Nutr. 130:2285-2291.

Hara, A., and N. S. Radin. 1978. Lipid extraction of tissues with a low-toxicity solvent. Anal. Biochem. 90:420-426.

Ip, C., S. Banni, E. Angioni, G. Carta, J. McGinley, H. J. Thompson, D. Barbano, and D. E. Bauman. 1999. Conjugated linoleic acidenriched butter fat alters mammary gland morphogenesis and reduces cancer risk in rats. J. Nutr. 129:2135-2142.

Jenness, R. 1985. Biochemical and nutritional aspects of milk and colostrum. Pages 164-197 in Lactation. B. L. Larson, ed. The Iowa State University Press, Ames, IA.

Jensen, R. G. 2002. The composition of bovine milk lipids: January 1995 to December 2000. J. Dairy Sci. 85:295-350.

Jiang, J., L. Bjoerck, R. Fonden, and M. Emanuelson. 1996. Occurrence of conjugated cis-9, trans-11-octadecadienoic acid in bovine milk: Effects of feed and dietary regimen. J. Dairy Sci. 79:438445.

Kelly, M. L., J. R. Berry, D. A. Dwyer, J. M. Griinari, P. Y. Chouinard, M. E. Van Amburgh, and D. E. Bauman. 1998a. Dietary fatty acid sources affect conjugated linoleic acid concentrations in milk from lactating dairy cows. J. Nutr. 128:881-885.

Kelly, M. L., E. S. Kolver, D. E. Bauman, M. E. Van Amburgh, and L. D. Muller. 1998b. Effect of intake of pasture on concentrations of conjugated linoleic acid in milk of lactating cows. J. Dairy Sci. 81:1630-1636.

Lawless, F., J. J. Murphy, D. Harrington, R. Devery, and C. Stanton. 1998. Elevation of conjugated cis-9, trans-11-octadecadienoic acid in bovine milk because of dietary supplementation. J. Dairy Sci. 81:3259-3267.

Lawless, F., C. Stanton, P. L'Escorp, R. Devery, P. Dillon, and J. J. Murphy. 1999. Influence of breed on bovine milk cis-9, trans-11 conjugated linoleic acid content. Livest. Prod. Sci. 62:43-49. 
Lock, A. L., and P. C. Garnsworthy. 2002. Independent effects of dietary linoleic and linolenic fatty acids on the conjugated linoleic acid content of cows' milk. Anim. Sci. 74:163-176.

Lock, A. L., and P. C. Garnsworthy. 2003. Seasonal variation in milk conjugated linoleic acid and $\Delta^{9}$-desaturase activity in dairy cows. Livest. Prod. Sci. 79:47-59.

Malau-Aduli, A. E. O., B. D. Siebert, C. D. K. Bottema, and W. S. Pitchford. 1997. A comparison of the fatty acid composition of triacylglycerols in adipose tissue from Limousin and Jersey cattle. Aust. J. Agric. Res. 48:715-722.

McGuire, M. A., and M. K. McGuire. 2000. Conjugated linoleic acid (CLA): A ruminant fatty acid with beneficial effects on human health. Proc Am. Soc. Anim. Sci. 1999. Available at: http://www.asas.org/jas/symposia/proceedings/0938.pdf.

Morales, M. S., D. L. Palmquist, and W. P. Weiss. 2000. Effects of fat source and copper on unsaturation of blood and milk triacylglycerol fatty acids in Holstein and Jersey cows. J. Dairy Sci. 83:2105-2111.

National Research Council. 2001. Nutrient requirements of dairy cattle, 7th rev. ed. National Academy of Sciences, Washington, DC.

Parodi, P. W. 1982. Positional distribution of fatty acids in the triglyceride classes of milk fat. J. Dairy Res. 49:73-80.

Peterson, D. G., J. A. Kelsey, and D. E. Bauman. 2002. Analysis of variation in cis-9, trans-11 conjugated linoleic acid (CLA) in milk fat of dairy cows. J. Dairy Sci. 85:2164-2172.
Piperova, L. S., J. Sampugna, B. B. Teter, K. F. Kalscheur, M. P. Yurawecz, Y. Ku, K. M. Morehouse, and R. A. Erdman. 2002. Duodenal and milk trans octadecenoic acid and conjugated linoleic acid (CLA) isomers indicate that postabsorptive synthesis is the predominant source of cis-9-containing CLA in lactating dairy cows. J. Nutr. 132:1235-1241.

SAS Institute, Inc. 2000. Release 8.1. Cary, NC.

Solomon, R., L. E. Chase, D. Ben-Ghedalia, and D. E. Bauman. 2000. The effect of nonstructural carbohydrate and addition of full fat extruded soybeans on the concentration of conjugated linoleic acid in the milk fat of dairy cows. J. Dairy Sci. 83:1322-1329.

Stanton, C., F. Lawless, G. Kjellmer, D. Harrington, R. Devery, J. F. Connolly, and J. Murphy. 1997. Dietary influences on bovine milk cis-9, trans-11 conjugated linoleic acid content. J. Food Sci. 62:1083-1086.

White, S. L., J. A. Bertrand, M. R. Wade, S. P. Washburn, J. T. Green, Jr., and T. C. Jenkins. 2001. Comparison of fatty acid content of milk from Jersey and Holstein cows consuming pasture of a total mixed ration. J. Dairy Sci. 84:2295-2301.

Whitlock, L. A., D. J. Schingoethe, A. R. Hippen, K. F. Kalscheur, R. J. Baer, N. Ramaswamy, and K. M. Kasperson. 2002. Fish oil and extruded soybeans fed in combination increase conjugated linoleic acid in milk of dairy cows more than when fed separately. J. Dairy Sci. 85:234-243. 